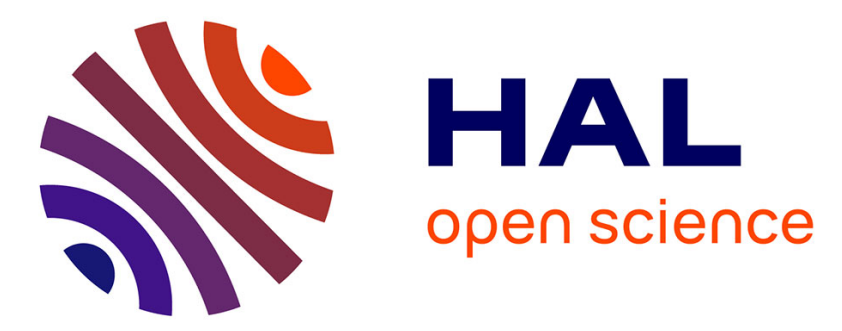

\title{
Cardiac Arrest and Mortality Related to Intubation Procedure in Critically Ill Adult Patients
}

Audrey de Jong, Amélie Rolle, Nicolas Molinari, Catherine Paugam-Burtz, Jean-Michel Constantin, Jean-Yves Lefrant, Karim Asehnoune, Boris Jung, Emmanuel Futier, Gerald Chanques, et al.

\section{To cite this version:}

Audrey de Jong, Amélie Rolle, Nicolas Molinari, Catherine Paugam-Burtz, Jean-Michel Constantin, et al.. Cardiac Arrest and Mortality Related to Intubation Procedure in Critically Ill Adult Patients. Critical Care Medicine, 2018, 46 (4), pp.532 - 539. 10.1097/CCM.0000000000002925 . hal-01739496

\section{HAL Id: hal-01739496 \\ https://hal.umontpellier.fr/hal-01739496}

Submitted on 24 Mar 2020

HAL is a multi-disciplinary open access archive for the deposit and dissemination of scientific research documents, whether they are published or not. The documents may come from teaching and research institutions in France or abroad, or from public or private research centers.
L'archive ouverte pluridisciplinaire HAL, est destinée au dépôt et à la diffusion de documents scientifiques de niveau recherche, publiés ou non, émanant des établissements d'enseignement et de recherche français ou étrangers, des laboratoires publics ou privés. 


\title{
Cardiac Arrest and Mortality Related to Intubation Procedure in Critically III Adult Patients: A Multicenter Cohort Study
}

\author{
Audrey De Jong, $\mathrm{MD}, \mathrm{PhD}^{1,2}$; Amélie Rolle, $\mathrm{MD}^{1,3}$; Nicolas Molinari, $\mathrm{PhD}^{4}$; \\ Catherine Paugam-Burtz, $\mathrm{MD}, \mathrm{PhD}^{5,6}$; Jean-Michel Constantin, $\mathrm{MD}, \mathrm{PhD}^{7}$; \\ Jean-Yves Lefrant, $\mathrm{MD}, \mathrm{PhD}^{8}$; Karim Asehnoune, $\mathrm{MD}, \mathrm{PhD}^{9}$; Boris Jung, $\mathrm{MD}, \mathrm{PhD}^{2,10}$; \\ Emmanuel Futier, $\mathrm{MD}, \mathrm{PhD}^{7}$; Gérald Chanques, $\mathrm{MD}, \mathrm{PhD}^{1,2}$; Elie Azoulay, $\mathrm{MD}, \mathrm{PhD}^{11}$; Samir Jaber, $\mathrm{MD}, \mathrm{PhD}^{1,2}$
}

\begin{abstract}
${ }^{1}$ Anesthesiology and Intensive Care, Anesthesia and Critical Care Department B, Saint Eloi Teaching Hospital, Unité INSERM U1046, Université Montpellier 1, Université Montpellier 2, Centre Hospitalier Universitaire Montpellier, Montpellier, France.

${ }^{2}$ INSERM U1046, CNRS UMR 9214, Montpellier, France.

${ }^{3}$ Department of Intensive Care \& Anesthesiology, University of Pointe à Pitre Hospital. Guadeloupe, France.

${ }^{4}$ Department of Statistics, University of Montpellier Lapeyronie Hospital, UMR 5149 IMAG, Montpellier, France.
\end{abstract}

${ }^{5}$ Department of Intensive Care \& Anesthesiology, University of Paris Diderot, Sorbonne Paris Cité, Paris, France.

${ }^{6}$ AP-HP, Hôpital Beaujon, Paris, France.

${ }^{7}$ Department of Intensive Care \& Anesthesiology, Hotel-Dieu Hospital, University Hospital of Clermont Ferrand, Clermont-Ferrand, France.

${ }^{8}$ Department of Intensive Care \& Anesthesiology, University of Montpellier, Nimes Hospital, Nimes, France.

${ }^{9}$ Department of Intensive Care \& Anesthesiology, University of Nantes, Hotel-Dieu Hospital, Nantes, France.

${ }^{10}$ Medical Intensive Care Unit, Lapeyronie Teaching Hospital, Centre Hospitalier Universitaire Montpellier, Montpellier, France.

${ }^{11}$ Medical Intensive Care Unit, University of Paris-Diderot, Saint Louis Hospital, Paris, France.

This study was performed at University of Montpellier, Montpellier University Hospital.

Drs. De Jong and Rolle contributed equally to this study. Drs. De Jong, Rolle, and Jaber contributed to study concept and design. Drs. De Jong, Rolle, and Chanques contributed in acquisition of the data. Drs. De Jong, Chanques, Azoulay, and Jaber contributed to data analysis and interpretation. Drs. De Jong, Rolle, Paugam-Burtz, Constantin, Lefrant, Asehnoune, Jung, Futier, Chanques, and Jaber contributed in article preparation and drafting. Drs. De Jong and Molinari contributed to statistical methods, statistical data analysis. Drs. Lefrant, Asehnoune, Jung, and Azoulay contributed in article critique and review. All authors approved the article submitted.

Supplemental digital content is available for this article. Direct URL citations appear in the printed text and are provided in the HTML and PDF versions of this article on the journal's website (http://journals.lww.com/ccmjournal).

Supported, in part, by institutional and/or departmental sources (Institutional University Hospital of Montpellier, 34000, France).

Dr. Asehnoune declares interest conflicts with LFB, Fresenius Kabi, Baxter companies. Dr. Futier declares interest conflicts with General Electric Medical
Systems and Fresenius Kabi companies. Dr. Jaber declares interest conflicts with Dräger, Hamilton, Maquet and Fisher Paykel Healthcare companies.

Dr. Asehnoune received funding for lectures from MSD, Fresenius Kabi, Baxter, and LFB. Dr. Futier received funding from Drager Medical, Edwards Lifesciences, Fresenius Kabi, General Electrics Healthcare, and Fisher \& Paykel Healthcare. Dr. Azoulay's institution received funding from Fisher \& Paykel, Gilead, Jazz Pharma, and Alexion. He received funding from lectures for Gilead, MSD, Alexion, Astellas, Baxter, and as a member of the board for Gilead. He also received support for article research from APHP. The remaining authors have disclosed that they do not have any potential conflicts of interest. For information regarding this article, E-mail: s-jaber@chu-montpellier.fr

Objectives: To determine the prevalence of and risk factors for cardiac arrest during intubation in ICU, as well as the association of ICU intubation-related cardiac arrest with 28-day mortality.

Design: Retrospective analysis of prospectively collected data.

Setting: Sixty-four French ICUs.

Patients: Critically ill patients requiring intubation in the ICU.

Interventions: None.

Measurements and Main Results: During the 1,847 intubation procedures included, 49 cardiac arrests (2.7\%) occurred, including 14 without return of spontaneous circulation (28.6\%) and 35 with return of spontaneous circulation (71.4\%). In multivariate analysis, the main predictors of intubation-related cardiac arrest were arterial hypotension (systolic blood pressure $<90 \mathrm{~mm} \mathrm{Hg}$ ) prior to intubation (odds ratio $=3.406$ [1.797-6.454]; $p=0.0002$ ), hypoxemia prior to intubation (odds ratio $=3.991$ [2.101-7.583]; $p<0.0001$ ), absence of preoxygenation (odds ratio $=3.584$ [1.287-9.985]; $p=0.0146$ ), overweight/obesity (body mass index $>25 \mathrm{~kg} / \mathrm{m}^{2}$; odds ratio $=2.005$ [1.017-3.951]; $p=0.0445$ ), and age more than 75 years old (odds ratio $=2.251[1.080-4.678] ; p=0.0297$ ). Overall 28-day mortality rate was $31.2 \%(577 / 1,847)$ and was significantly higher in patients who experienced intubation-related cardiac arrest than in noncardiac arrest patients $(73.5 \%$ vs $30.1 \% ; p<0.001)$. After multivariate analysis, intubation-related cardiac arrest was an independent risk factor for 28-day mortality (hazard ratio $=3.9$ [2.4-6.3]; $p<0.0001$ ).

Conclusions: ICU intubation-related cardiac arrest occurs in one of 40 procedures with high immediate and 28-day mortality. We identified five independent risk factors for cardiac arrest, three of 
which are modifiable, possibly to decrease intubation-related cardiac arrest prevalence and 28-day ICU mortality. (Crit Care Med 2018; 46:532-539)

Key Words: airway; cardiac arrest; critical care; intubation; mechanical ventilation

$\tau$ r ntubation is one of the most commonly performed highrisk procedures (1) in ICUs (2). Severe hypoxemia, cardiovascular collapse, and difficult intubation are the most frequent intubation-related complications (2-4). To prevent and limit the prevalence of severe hypoxemia and severe collapse following the intubation procedure and associated complications, specific risk factors for complications related to intubation (3) and difficult intubation in the ICU (2) have been identified and several preoxygenation techniques and intubation algorithms have been developed (5-8).

However, intubation-related cardiac arrest in critically ill adult patients has been less studied (2, 3, 7, 9-12). Studies published so far were not adequately powered to evaluate this outcome and were rather focused on severe hypoxemia and/or severe collapse related to intubation (2-4). One retrospective study (13) did assess the prevalence and etiology of cardiac arrests during emergency intubation outside the operating room. However, the studied intubation procedures were not performed only in the ICU (26/60), but also outside the ICU (34/60), in wards or emergency departments, and patient or procedure characteristics recorded prior to intubation were not assessed.

To our knowledge, there is no recent prospective study which specifically analyzed the risk factors for ICU intubation procedure-related cardiac arrest.

The main objectives of our study were to establish the prevalence of cardiac arrest during the intubation procedure, the mortality rate of patients suffering cardiac arrest, immediately and at day 28, and to assess the risk factors for cardiac arrest and 28-day mortality in a large cohort of ICU intubation procedures. We hypothesized that intubation-related cardiac arrest is not uncommon and is associated with high morbidity and mortality and that potentially modifiable risk factors could be identified.

\section{MATERIALS AND METHODS}

\section{Setting and Study Design}

We retrospectively analyzed data from intubation procedures collected in six prospective randomized and observational studies using five databases $(2-4,6,8,14)$, in 64 ICUs overall. For each study, similar data were collected before, during, and after intubation procedures using the same methodology. Institutional Review Board approval was obtained for each study. Detailed information is available in Supplemental Table 1 (Supplemental Digital Content 1, http://links.lww.com/CCM/D120).

\section{Inclusion and Exclusion Criteria}

All intubation procedures performed in ICU were included for patients 18 years old and older. Patients admitted for cardiac arrest or intubated for cardiac arrest were excluded from the analysis.

\section{Definitions and Outcome Measures}

The primary outcome was intubation-related cardiac arrest. Cardiac arrest was defined as asystole, bradycardia, or ventricular dysrhythmia with nonmeasurable blood pressure during or within 5 minutes after intubation, requiring cardiopulmonary resuscitation (13). Secondary outcomes were cardiac arrest without return of spontaneous circulation (ROSC), severe and moderate complications related to intubation, and long-term outcome (mortality rate of patients suffering from cardiac arrests at day 28, length of stay in ICU). Severe complications were defined as follows: severe hypoxemia (defined by saturation nadir $<80 \%$, or decrease in saturation $>10 \%$ in case of maximal saturation before intubation $<90 \%$ ), severe cardiovascular collapse (defined as systolic blood pressure [SBP $]<65 \mathrm{~mm} \mathrm{Hg}$ recorded at least once or $<90 \mathrm{~mm} \mathrm{Hg}$ lasting $30 \mathrm{~min}$ despite $500-1,000 \mathrm{~mL}$ of fluid loading [crystalloid solutions] or decrease of SBP $>20 \%$ if $<65 \mathrm{~mm} \mathrm{Hg}$ before intubation or requiring introduction or increasing doses by $>30 \%$ of vasoactive support), cardiac arrest, and death during intubation (cardiac arrest without $\operatorname{ROSC})(2,3,8)$. Moderate complications were defined as follows: difficult intubation $(>2$ attempts), severe ventricular or supraventricular arrhythmia requiring intervention, esophageal intubation, agitation, pulmonary aspiration, and dental injuries $(2,3,8)$.

\section{Patient, Provider, and Practice Characteristics}

Patient baseline characteristics were recorded: demographic and epidemiologic data (age, sex, body mass index [BMI]), severity scores (Simplified Acute Physiologic Score [SAPS] II at admission, Sequential Organ Failure Assessment [SOFA] score on the day of the procedure), type of admission, reason for ICU admission, indication for intubation procedures, comorbidities, information given to the patient concerning intubation procedure, presence of nasogastric tube prior to intubation procedure, lowest peripheral capillary oxygen saturation $\left(\mathrm{SpO}_{2}\right)$ prior to intubation procedure (hypoxemia prior to intubation was defined as a $\mathrm{Spo}_{2}$ nadir $<80 \%$, regardless of oxygen flow rate, during the $4 \mathrm{hr}$ preceding intubation), lowest SBP prior to intubation procedure (arterial hypotension was defined as SBP $<90 \mathrm{~mm} \mathrm{Hg}$ ), presence of vasopressor drugs, and existence of predictive criteria of difficult intubation evaluated by the Mallampati score III or IV, obstructive sleep apnea syndrome, reduced mobility of cervical spine, limited mouth opening, coma, severe hypoxia, nonanesthesiologist as operator (MACOCHA) score (2). Provider and practice characteristics were recorded. During the intubation procedure, data were collected for preoxygenation, noninvasive ventilation (NIV) use for preoxygenation, hypnotic and neuromuscular blocker use, number of operators and attempts, Cormack grade, traction force on the laryngoscope, difficult intubation ( $>2$ attempts), and capnography use.

\section{Power and Sample Size}

Power calculation was performed a priori to ensure that the study would be sufficiently powered to detect clinically important differences in exposure variables (15), assuming a power 
of 0.80 , a significance level of $0.05,2.4 \%$ prevalence of primary outcome (2), and an estimated available sample size of 1,847 in the five studies. With a two-sided $t$ test, we would be able to detect an absolute difference of greater than or equal to 5.1\% in primary outcome (cardiac arrests during intubation procedure) between exposure and nonexposure groups for exposure prevalence ranging from $10 \%$ to $50 \%$ (15).

\section{Data Analysis}

Quantitative variables were expressed as means (SD) or medians (interquartile ranges, 25-75\%) and compared using the student $t$ test or the Wilcoxon test as appropriate (Gaussian or non-Gaussian variables) between patients who presented with cardiac arrest (cardiac arrest group) and those who did not present with cardiac arrest (no cardiac arrest group). Qualitative variables were expressed as numbers (percentage) and compared using the chi-square test or the Fisher test, as appropriate. First, to search for risk factors of intubation-related cardiac arrest, a multivariate logistic regression was performed. Interactions between variables were tested. All patient, provider, and practice characteristics with $p$ value of less than 0.20 in the univariate analysis were entered into the model, and a stepwise procedure was used to select the final model. The Hosmer-Lemeshow test was used to assess the goodness of fit of the logistic model (16). Area under the receiver operating curve (ROC) curve of the final model was assessed, and 2,000 bootstrapped samples were used for internal validation (17). Second, sensitivity analyses were computed, through other multivariate final models, forcing the following variables: first intubation and difficult intubation in the second model (2, 4 ), and nature of hypnotic used, use of neuromuscular blockers and fluid loading in the third model (4), and emergency degree of intubation (real vs deferred or relative) in the fourth model. Third, we compared cardiac arrests with ROSC to cardiac arrests without ROSC to assess specific risk factors for death (i.e., cardiac arrest without ROSC) subsequent to cardiac arrest. Finally, a Kaplan-Meier analysis was performed to determine the survival for 28-day survival, and a log-rank test was used to compare the two curves (cardiac arrest vs no cardiac arrest). Hazard ratios (HRs) of mortality between cardiac arrest and no cardiac arrest patients were obtained by the Cox method. Then a multivariate analysis using a Cox model was performed to determine the independent factors associated with 28-day mortality. All patient, provider, and practice characteristics with $p$ value of less than 0.20 in the univariate analysis were entered into the model, and a stepwise procedure was used to select the final model. The statistical analysis was done with the help of a statistical software (SAS, version 9.3; SAS Institute, Cary, NC). A $p$ value of less than 0.05 was considered significant.

\section{RESULTS}

\section{Prevalence of Intubation-Related Cardiac Arrest}

A total of 1,918 intubation procedures were reported from the five datasets in 64 ICUs from January 2001 to January 2016, after removing duplicates. After exclusion of cardiac arrests as a reason for admission and/or intubation, 1,847 intubations were included (Fig. 1). Forty-nine intubation-related cardiac arrests were recorded (2.7\% 95\% CI [2.0-3.4]).

\section{Patient, Provider, Practice Characteristics}

Patient baseline, provider, and practice characteristics are described in Table 1. The most common indications for intubation procedures were acute respiratory failure $(n=719$; $39 \%)$ and coma $(n=342 ; 21 \%)$. Anesthesiologists were the first providers in $68 \%$, and neuromuscular blockade was used in $80 \%$ of intubation procedures (73\% succinylcholine, $11 \%$ rocuronium, and 15\% other neuromuscular blockers).

\section{Factors Associated With Intubation-Related Cardiac Arrest}

Based on the univariate analysis (Table 1; and Supplemental Table 2, Supplemental Digital Content 1, http://links.lww.com/ CCM/D120), SOFA score, BMI, age more than 75 years old, shock as a reason for ICU admission or for intubation, alcohol abuse, low SBP prior to intubation, hypoxemia prior to intubation, first intubation, intubation in real emergency, presence of nasogastric tube, absence of use of hypnotics for induction, MACOCHA

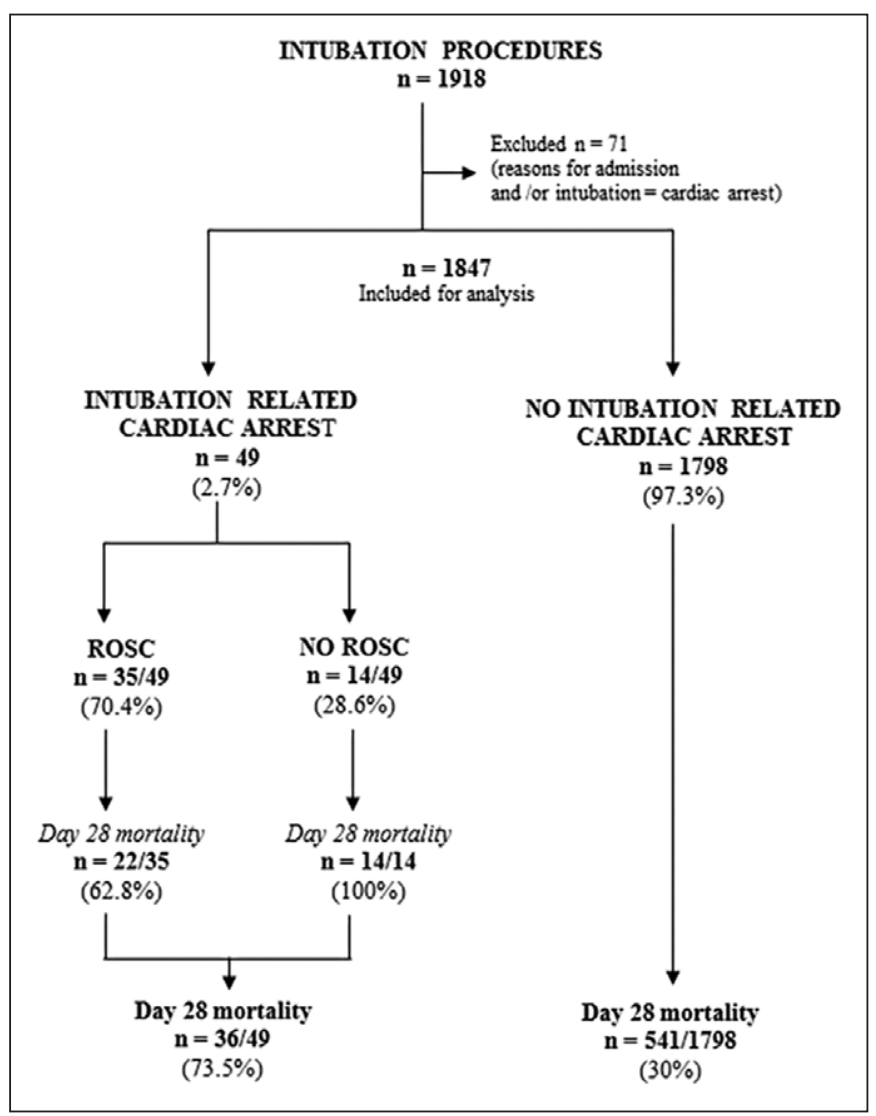

Figure 1. Flow chart of the study. One-thousand nine-hundred eighteen intubation procedures from five studies were included: De Jong et al (2), Jaber et al (3), Jaber et al (8), De Jong et al (6), and Baillard et al (14). After excluding patients with cardiac arrest at admission or at the beginning of intubation, 1,847 intubation procedures were included. Among them, 49 were complicated by cardiac arrests (35 with return of spontaneous circulation [ROSC] and 14 with no ROSC). 


\section{TABLE 1. Patient Baseline, Provider, and Practice Characteristics}

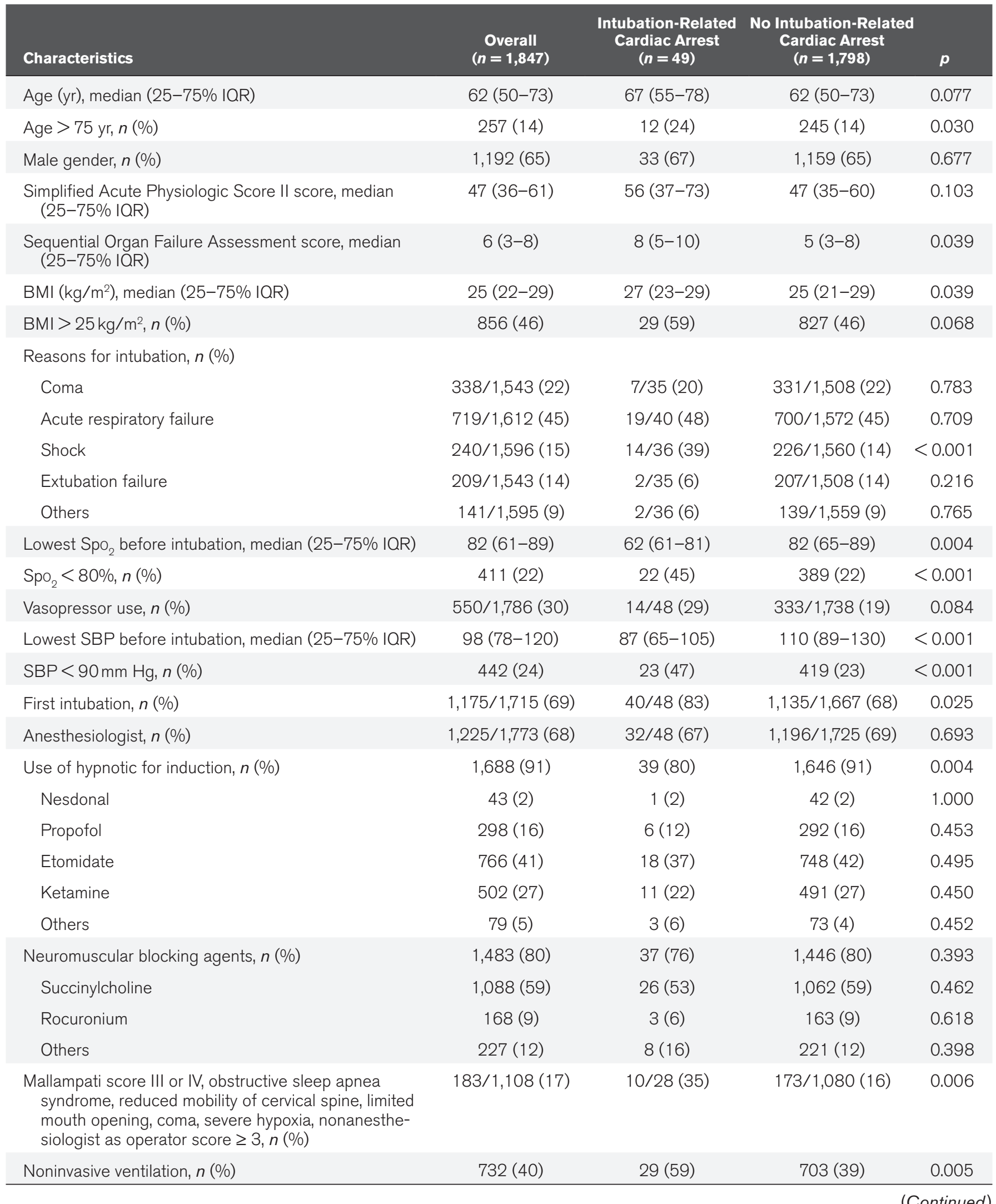


TABle 1. (Continued). Patient Baseline, Provider, and Practice Characteristics

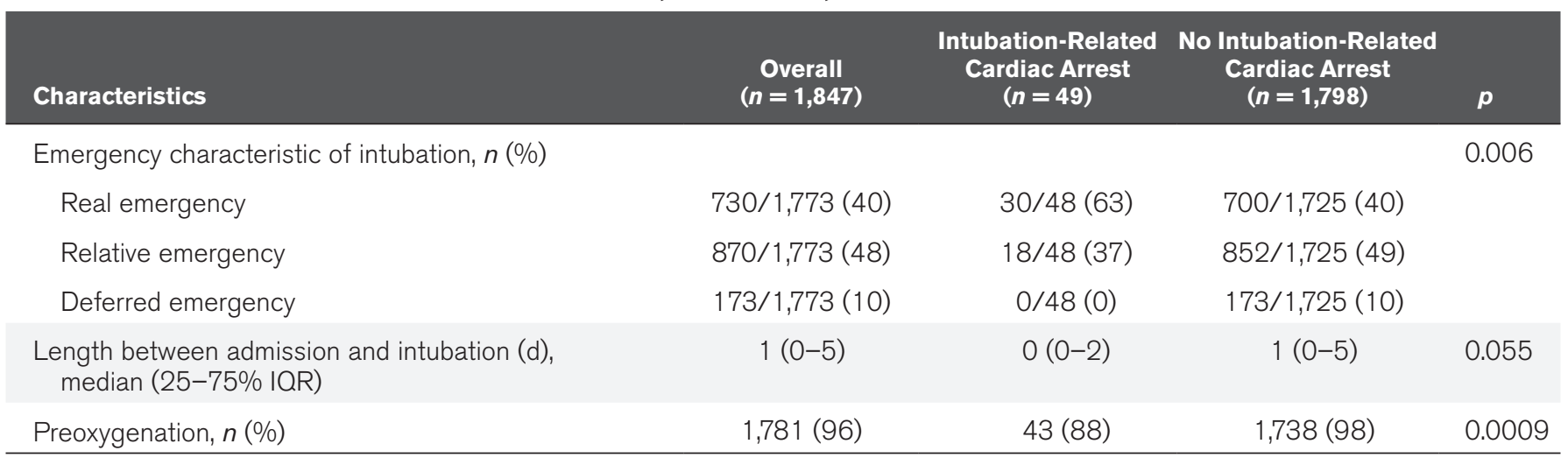

$\mathrm{BMI}=$ body mass index, IQR $=$ interquartile range, $\mathrm{SBP}=$ systolic blood pressure, $\mathrm{SpO}_{2}=$ peripheral capillary $\mathrm{O}_{2}$ saturation.

The emergency characteristic of intubation was categorized as follows: real emergency, intubation required without any delay; relative emergency, intubation required within $1 \mathrm{hr}$; deferred emergency, intubation required in $>1 \mathrm{hr}$.

score, obstructive apnea syndrome, low thyromental distance, neck circumference, no preoxygenation, and need to release Sellick maneuver for intubation were significantly associated with cardiac arrests. Succinylcholine use was not associated with increased intubation-related cardiac arrest (26/1,088 [2.4\%]) compared with rocuronium use $(3 / 168[1.8 \%] ; p=0.79)$, other neuromuscular blocker use $(8 / 227$ [3.5\%]; $p=0.36)$, or absence of neuromuscular blocker use (12/364 [3.3\%]; $p=0.35)$.

By multivariate analysis, arterial hypotension (SBP < $90 \mathrm{~mm} \mathrm{Hg}$ ) prior to intubation (odds ratio $[\mathrm{OR}]=3.406$ [1.797-6.454]; $p=0.0002)$, hypoxemia prior to intubation $(\mathrm{OR}=3.991[2.101-7.583] ; p<0.0001)$, absence of preoxygenation $(\mathrm{OR}=3.584$ [1.287-9.985]; $p=0.0146)$, overweight/obesity $\left(\mathrm{BMI}>25 \mathrm{~kg} / \mathrm{m}^{2} ; \mathrm{OR}=2.005[1.017-3.951] ; p=0.0445\right)$, and age more than 75 years old $(\mathrm{OR}=2.251[1.080-4.678]$; $p=0.0297)$ were the five identified independent risk factors for cardiac arrest (Supplemental Fig. 1A, Supplemental Digital Content 1, http://links.lww.com/CCM/D120). The $p$ value of the goodness of fit, assessed by the Hosmer and Lemeshow test, was 0.49 , showing acceptable adequacy with data. Area under the ROC curve was 0.79 (0.72-0.87). After internal validation by bootstrap, the area under the ROC curve was 0.79 (0.73-0.86). After sensitivity analysis, main independent risk factors significantly associated with cardiac arrests were the same in the second and the third models (Supplemental Fig. 1, $\boldsymbol{B}$ and $\boldsymbol{C}$, Supplemental Digital Content 1, http://links.lww. com/CCM/D120) as in the main final model (Supplemental Fig. 1A, Supplemental Digital Content 1, http://links.lww.com/

\section{TABLE 2. Outcomes According to Intubation-Related Cardiac Arrest}

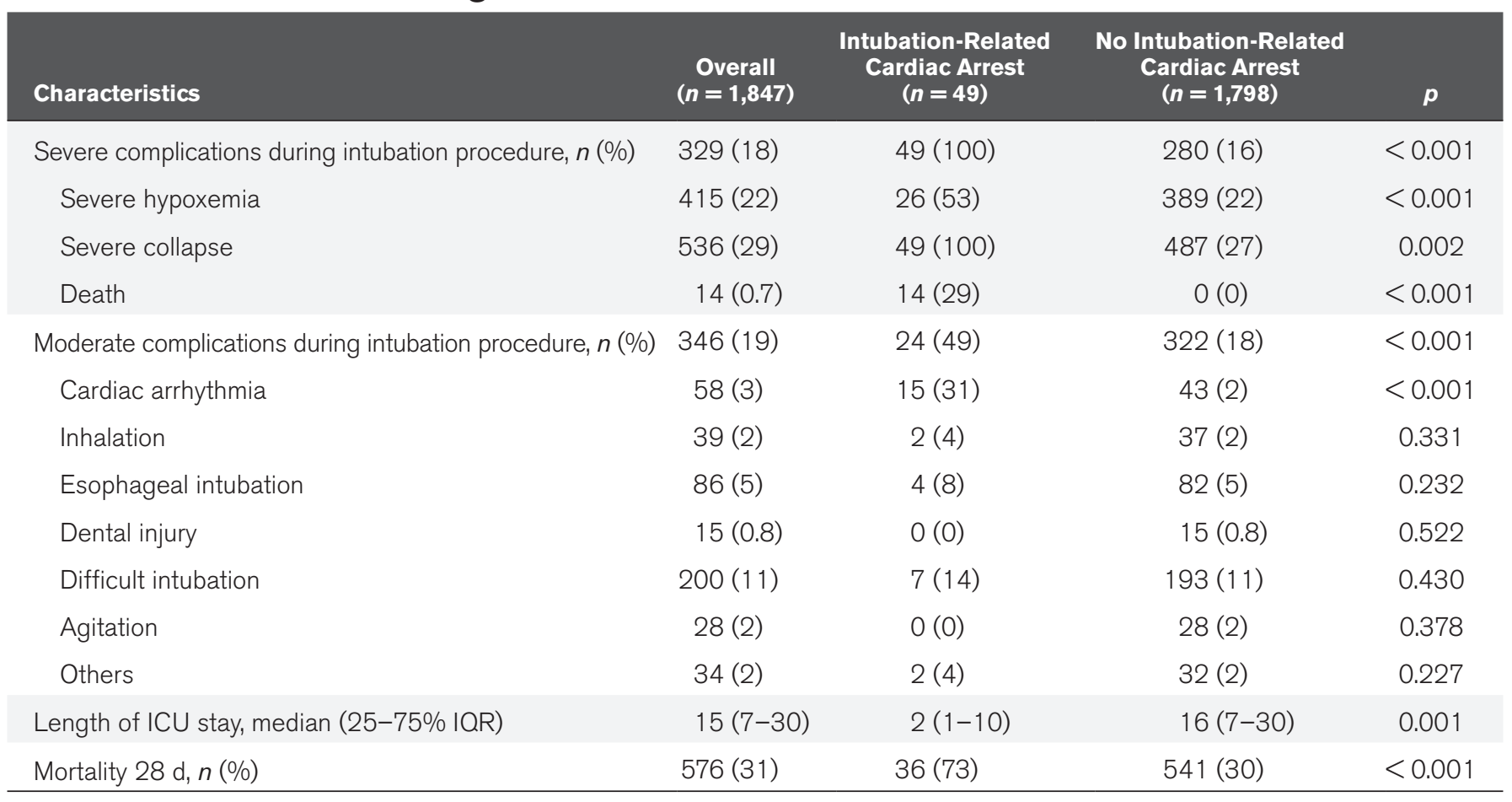

$\mathrm{IQR}=$ interquartile range. 
CCM/D120). All but one (overweight or obesity) of the same risk factors as in the main analysis were encountered in the fourth model (Supplemental Fig. 1D, Supplemental Digital Content 1, http://links.lww.com/CCM/D120). OR of intubation-related cardiac arrest according to the number of risk factors are presented in Supplemental Figure $\mathbf{1 E}$ (Supplemental Digital Content 1, http://links.lww.com/CCM/D120).

\section{Outcomes}

Severe and moderate complications associated with cardiac arrest are described in Table 2. Patients who did not experience intubation-related cardiac arrest had a significantly lower mortality rate at day $28(30.1 \%, 541 / 1,798)$ than patients who had cardiac arrest $(73.5 \%, 36 / 49 ; p<0.0001)$ (Fig. 1), including cardiac arrest with ROSC $(62.8 \%, 22 / 35 ; p<0.0001)$ (Fig. 1). Kaplan-Meier curves of 28-day mortality according to intubation-related cardiac arrest are presented in Figure 2 (log-rank test $p<0.0001$; HR = 4.3 [95\% CI, 3.1-6.2]). Twenty-one cardiac arrest patients (45\%) died within 48 hours, and 33 cardiac arrest patients (70\%) died within 28 days. Intubation-related cardiac arrest was an independent risk factor for day 28 mortality $(\mathrm{HR}=3.9$ [95\% CI, 2.4-6.3]; $p<0.0001$ ), after adjustment for age, SAPS II, and shock state as reason for admission (Supplemental Table 3, Supplemental Digital Content 1, http://links.lww.com/CCM/D120).

\section{Return of Spontaneous Circulation}

Patients failed to attain a ROSC following 14 of these 49 intubation-related cardiac arrests (28.6\% of cardiac arrests). Patient, provider, and practice characteristics were similar between the patients with and without ROSC, except for diabetes, Mallampati III/IV, absence of nasogastric tube, and arterial

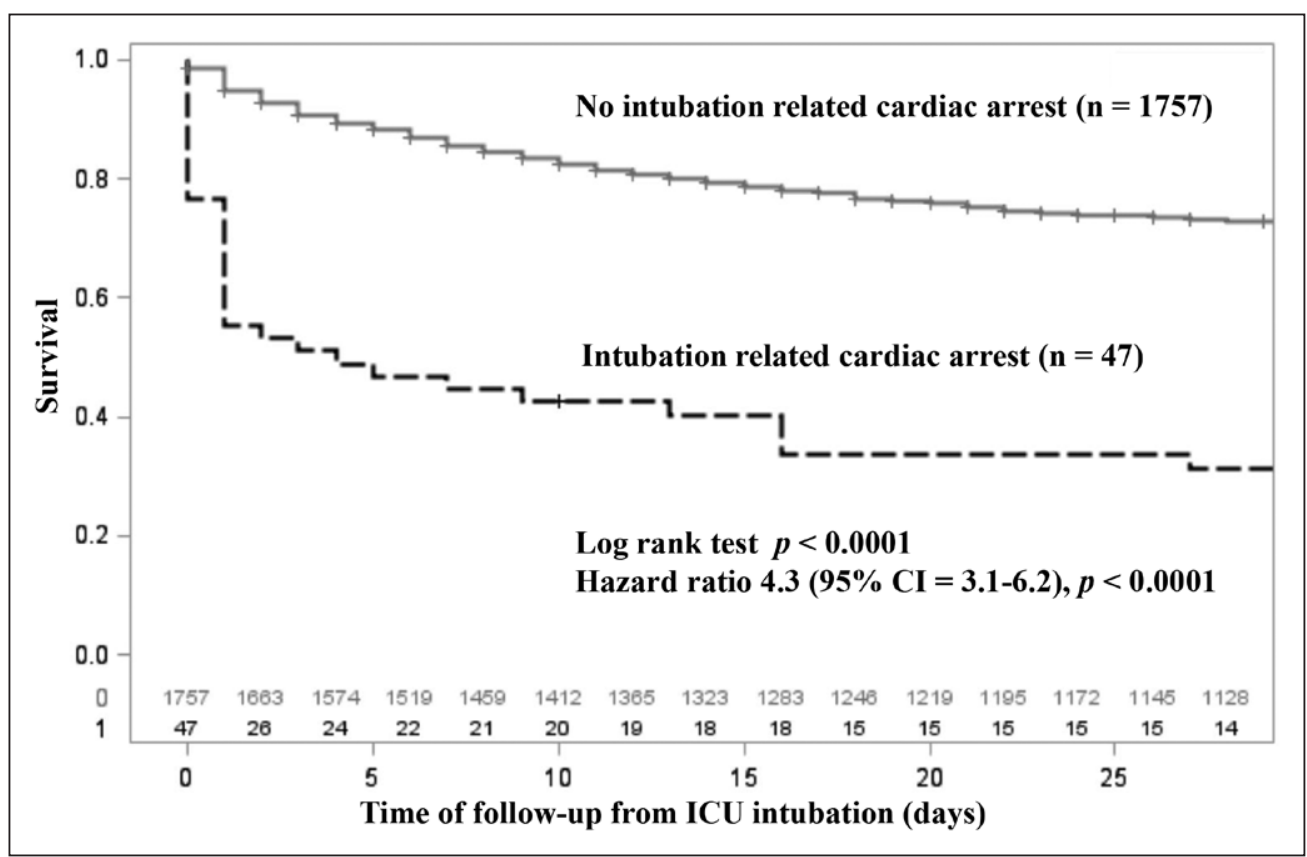

Figure 2. Kaplan-Meier curves of 28-d mortality according to cardiac arrest during intubation. Kaplan-Meier curves of 28-d mortality according to intubation-related cardiac arrest are presented (log-rank test $p<0.0001$, hazard ratio $=4.3$ [95\% Cl], 3.1-6.2). The Kaplan-Meier curves were built on 1,804 patients. For two patients in the group with intubation-related cardiac arrest and 41 patients in the group without intubation-related cardiac arrest, the status of mortality at day 28 was available but not the time of follow-up. hypotension ( $\mathrm{SBP}<90 \mathrm{~mm} \mathrm{Hg}$ ), which were significantly more frequent in the group without ROSC (Supplemental Tables 4 and 5, Supplemental Digital Content 1, http://links.lww.com/ CCM/D120). Outcomes of patients with and without ROSC are presented in Supplemental Table 6 (Supplemental Digital Content 1, http://links.lww.com/CCM/D120).

\section{DISCUSSION}

Intubation-related cardiac arrest was recorded in 49 of 1,847 ICU intubation procedures $(2.7 \%)$. It was associated with high immediate and 28 -day mortality rates (28.5\% and $71.4 \%$, respectively) (Figs. 1 and 2) and was determined to be an independent risk factor for day 28 mortality $(\mathrm{HR}=3.9$ [2.4-6.3]; $p<0.0001)$ (Supplemental Table 3, Supplemental Digital Content 1, http:// links.lww.com/CCM/D120). To predict intubation-related cardiac arrest, five independent risk factors were identified, with three potentially actionable high-risk factors (hypoxemia prior to intubation, hemodynamic failure prior to intubation, absence of preoxygenation) that may respond to preventive approaches. Patient characteristics were also identified to be associated with cardiac arrest: BMI greater than $25 \mathrm{~kg} / \mathrm{m}^{2}$ (being overweight or obese) and age more than 75 years old were risk factors (Supplemental Fig. 1A, Supplemental Digital Content 1, http://links. lww.com/CCM/D120). The final model was consistent after sensitivity analysis (Supplemental Fig. $1 B-D$, Supplemental Digital Content 1, http://links.lww.com/CCM/D120) and confirmed after internal validation by bootstrap analysis.

We chose to specifically focus this study on the "cardiac arrest" outcome complication. Cardiac arrest is the major lifethreatening intubation-related complication and is challenging to prevent. In the present study, cardiac arrest prevalence during intubation was not low $(2.7 \%)$, especially when compared with cardiac arrest prevalence during intubation for elective surgery (0.019\%) (18). Intubation-related cardiac arrest is therefore more than 100 times more frequent in an ICU setting than in an operative room setting. Considering that $12 \%$ of patients admitted to ICU will undergo an intubation procedure (2), and that there are an average of 10 ICU beds for 100,000 inhabitants in the more developed nations (19, 20), more than 25,000 intubation-related cardiac arrests are likely to occur each year worldwide.

Intubation-related cardiac arrest was a major predictive factor of mortality in the ICU 
patients; 28-day mortality was more than three-fold higher when a cardiac arrest occurred during an intubation procedure, after adjustment for potential confounding variables $(\mathrm{HR}=3.9$ [95\% CI, 2.4-6.3]; $p<0.0001)$. Reducing prevalence of intubation-related cardiac arrest is crucial in this context. This study is the first adequately powered to assess risk factors for intubation-related cardiac arrest. Using the five studies, we performed for ICU intubation-related complications, all with similar data collection and methodology, 1,847 intubation procedures were included. The risk factors found for each intubation-related complication, including those identified in the present study for intubation-related cardiac arrest, are summarized in Supplemental Table 7 (Supplemental Digital Content 1, http://links.lww.com/CCM/D120). It is worthy to note that severe hypoxemia was the main common risk factor for difficult intubation, severe collapse, cardiac arrest, and overall complications.

Identifying patients who are at high risk for cardiac arrest during intubation has several implications in clinical practice. These results highlight interventions that may reduce the likelihood of intubation-related cardiac arrest and therefore 28-day mortality. These interventions potentially include 1) optimizing preoxygenation using NIV and providing oxygen with high-flow nasal cannula oxygen (HFNC) throughout intubation procedure attempts (i.e., apneic oxygenation) to minimize hypoxemia $(21,22), 2)$ aggressive hemodynamic support before and during intubation procedures (8), and 3) special planning, including application of a standardized protocol for difficult intubation (5). However, intubation-related cardiac arrests were more frequent during real emergency or relative emergency intubations, and time might be too limited to modify preoxygenation, hemodynamics, or intubation devices in case of extreme emergency. In these emergent situations, the risk factors for cardiac arrest may not be modifiable. However, these modifiable risk factors were independently associated with intubation-related cardiac arrest after adjusting for the emergency degree of intubation (Supplemental Fig. 1D, Supplemental Digital Content 1, http:// links.lww.com/CCM/D120).

Our study has several limitations. First, the possibility of reporting bias and inaccuracy cannot be eliminated in this prospective multicenter observational study. However, the data were collected precisely in an attempt to minimize selfreporting bias and to improve data accuracy. Second, because this is a cohort study, we were not able to eliminate the effect of unmeasured confounders when each factor was evaluated for its association with cardiac arrest. In particular, effect of delayed intubation in patients under NIV (23) or HFNC (2426) was not assessed and could be a major risk factor for cardiac arrest during intubation procedure. Third, some data were missing in the oldest datasets and could not be found retrospectively. Finally, the five databases were not designed to specifically assess cardiac arrest outcomes and cannot give reliable data for event chronology. However, the baseline patient, provider, and procedure characteristics as the main outcomes were prospectively collected with the same methodology, which limits the potential biases.

\section{CONCLUSIONS}

Intubation-related cardiac arrest occurred in one of 40 cases of ICU intubation procedures. Main risk factors for intubationrelated cardiac arrest were overweight or obesity, age more than 75 years old, low SBP prior to intubation, hypoxemia prior to intubation, and absence of preoxygenation before intubation procedure. Interventions before and during intubation procedures to improve hemodynamic status and minimize preintubation hypoxemia may prevent intubation-related cardiac arrest and thereby decrease 28-day mortality of ICU patients placed under invasive mechanical ventilation.

\section{AKNOWLEDGMENTS}

We are grateful to Dr. Julie Carr, Department of Anesthesia and Intensive Care, Saint-Eloi University Hospital, Centre Hospitalier Universitaire Montpellier, Montpellier, F-34295, France for her English editing.

\section{REFERENCES}

1. Roux D, Reignier J, Thiery G, et al: Acquiring procedural skills in ICUs: A prospective multicenter study*. Crit Care Med 2014; 42:886-895

2. De Jong A, Molinari N, Terzi N, et al; AzuRéa Network for the FridaRéa Study Group: Early identification of patients at risk for difficult intubation in the intensive care unit: Ddevelopment and validation of the MACOCHA score in a multicenter cohort study. Am J Respir Crit Care Med 2013; 187:832-839

3. Jaber S, Amraoui J, Lefrant JY, et al: Clinical practice and risk factors for immediate complications of endotracheal intubation in the intensive care unit: A prospective, multiple-center study. Crit Care Med 2006; 34:2355-2361

4. Perbet S, De Jong A, Delmas J, et al: Incidence of and risk factors for severe cardiovascular collapse after endotracheal intubation in the ICU: A multicenter observational study. Crit Care 2015; 19:257

5. De Jong A, Jung B, Jaber S: Intubation in the ICU: We could improve our practice. Crit Care 2014; 18:209

6. De Jong A, Clavieras N, Conseil M, et al: Implementation of a combo videolaryngoscope for intubation in critically ill patients: A before-after comparative study. Intensive Care Med 2013; 39:2144-2152

7. De Jong A, Molinari N, Conseil M, et al: Video laryngoscopy versus direct laryngoscopy for orotracheal intubation in the intensive care unit: A systematic review and meta-analysis. Intensive Care Med 2014; 40:629-639

8. Jaber $\mathrm{S}$, Jung $\mathrm{B}$, Corne $\mathrm{P}$, et al: An intervention to decrease complications related to endotracheal intubation in the intensive care unit: A prospective, multiple-center study. Intensive Care Med 2010; 36:248-255

9. Griesdale DE, Bosma TL, Kurth T, et al: Complications of endotracheal intubation in the critically ill. Intensive Care Med 2008; 34:1835-1842

10. Bowles TM, Freshwater-Turner DA, Janssen DJ, et al; RTIC Severn Group: Out-of-theatre tracheal intubation: Prospective multicentre study of clinical practice and adverse events. $\mathrm{Br} J$ Anaesth 2011; 107:687-692

11. Simpson GD, Ross MJ, McKeown DW, et al: Tracheal intubation in the critically ill: A multi-centre national study of practice and complications. Br J Anaesth 2012; 108:792-799

12. Mort TC: Emergency tracheal intubation: Complications associated with repeated laryngoscopic attempts. Anesth Analg 2004; 99:607613 , table of contents

13. Mort TC: The incidence and risk factors for cardiac arrest during emergency tracheal intubation: A justification for incorporating the ASA Guidelines in the remote location. J Clin Anesth 2004; $16: 508-516$ 
14. Baillard C, Fosse JP, Sebbane M, et al: Noninvasive ventilation improves preoxygenation before intubation of hypoxic patients. $\mathrm{Am} \mathrm{J}$ Respir Crit Care Med 2006; 174:171-177

15. Shiima Y, Berg RA, Bogner HR, et al; National Emergency Airway Registry for Children Investigators: Cardiac arrests associated with tracheal intubations in picus: A multicenter cohort study. Crit Care Med 2016; 44:1675-1682

16. Lemeshow S, Hosmer DW Jr: A review of goodness of fit statistics for use in the development of logistic regression models. Am J Epidemiol $1982 ; 115: 92-106$

17. Steyerberg EW, Harrell FE Jr, Borsboom GJ, et al: Internal validation of predictive models: Efficiency of some procedures for logistic regression analysis. J Clin Epidemio/ 2001; 54:774-781

18. Bainbridge D, Martin J, Arango M, et al; Evidence-based Peri-operative Clinical Outcomes Research (EPiCOR) Group: Perioperative and anaesthetic-related mortality in developed and developing countries: A systematic review and meta-analysis. Lancet 2012; 380:1075-1081

19. Prin $M$, Wunsch $H$ : International comparisons of intensive care: Informing outcomes and improving standards. Curr Opin Crit Care 2012; 18:700-706

20. Murthy S, Wunsch H: Clinical review: International comparisons in critical care - lessons learned. Crit Care 2012; 16:218
21. Jaber S, Molinari N, De Jong A: New method of preoxygenation for orotracheal intubation in patients with hypoxaemic acute respiratory failure in the intensive care unit, non-invasive ventilation combined with apnoeic oxygenation by high flow nasal oxygen: The randomised OPTINIV study protocol. BMJ Open 2016; 6:e011298

22. Jaber S, Monnin M, Girard M, et al: Apnoeic oxygenation via high-flow nasal cannula oxygen combined with non-invasive ventilation preoxygenation for intubation in hypoxaemic patients in the intensive care unit: The single-centre, blinded, randomised controlled OPTINIV trial. Intensive Care Med 2016; 42:1877-1887

23. Delbove A, Darreau C, Hamel JF, et al: Impact of endotracheal intubation on septic shock outcome: A post hoc analysis of the SEPSISPAM trial. J Crit Care 2015; 30:1174-1178

24. Esquinas AM, Parke R, Gifford AH: Failure of high-flow nasal cannula and delayed intubation: A new harmful sequence? Intensive Care Med 2015; 41:1170

25. Demoule A, Rello J: High flow oxygen cannula: The other side of the moon. Intensive Care Med 2015; 41:1673-1675

26. Ricard JD, Messika J, Sztrymf B, et al: Impact on outcome of delayed intubation with high-flow nasal cannula oxygen: Is the device solely responsible? Intensive Care Med 2015; 41:1157-1158 